\title{
Research governance: where did it come from, what does it mean?
}

\author{
Sara Shaw Petra M Boynton Trisha Greenhalgh
}

$J$ R Soc Med 2005;98:496-502

This is the first in a series of three articles on research governance.

\section{SUMMARY}

For a variety of historical and social reasons, research has become increasingly formalized and regulated. This change has potential benefits (reduction in fraud and misconduct, protection of vulnerable groups, financial probity) but also disadvantages (increased paperwork, time delays, constraints on research freedom).

The terms 'research' and 'governance' mean different things in different contexts. Even with explicit guidance, ambiguities must be resolved by human judgement. Variation in the nature and outcome of approval decisions is therefore a fact of life.

The type of approval needed for a research study depends on the official remit of the approval body, the question to be addressed; the methods to be used; the context in which the work will take place; the level of analysis and interpretation; and the plans for how the findings will be presented and used.

\section{INTRODUCTION}

In many countries, research has moved from being a largely unregulated endeavour undertaken by interested individuals working independently of external controls to a highly formalized, regulated and institutionalized activity. ${ }^{1}$ This change has a number of historical and social causes, including an increase in the scale of research and national funding to support it, the expectation for greater accountability in the public sector; the active input of service users (e.g. gay men and AIDS $^{2}$ ), and the exposure of fraud and misconduct in research-especially on groups who have lacked the ability or opportunity to give informed consent (Box 1). ${ }^{3}$

In the UK, the rapid growth of systems and procedures for research management and governance has generated

Open Learning Unit, Department of Primary Care and Population Sciences, University College London, Holborn Union Building, Highgate Hill, London N19 5LW, UK

Correspondence to: Sara Shaw

E-mail: s.shaw@pcps.ucl.ac.uk
Box 1 Fraud and misconduct in medical research: disproportionate impact on vulnerable groups

\section{Minority ethnic groups}

Between the 1930s and 1960s in Tuskegee in the South of America 400 poor, Black men from rural areas were recruited without their knowledge or consent into a long-term followup trial of the prognosis of untreated syphilis; effective treatments were withheld from them for decades. ${ }^{26}$ Jews, Gypsies and Slavs were included within human experiments throughout the Holocaust, particularly those relating to warfare such as the testing of effects of gas attacks, battle injury or surviving freezing temperatures subjected to a range of experimentation [Ref. 3].

\section{Institutionalized groups}

Prisoners [Refs 3, 27] and military personnel [Ref. 3] have not always been given the opportunity to give full informed consent or opt out of research without changes in their care or status.

\section{Developing countries}

Poor communities in developing countries have occasionally been targeted by pharmaceutical companies for trials of medicinal products that would not meet stringent restrictions in the countries where the company is based [Refs 28, 29].

\section{Socially excluded groups}

Studies of 'treatments' for homosexuality up to the 1970s can, with the wisdom of hindsight, be classified as ideologically driven research that supported and perpetuated social prejudice and exclusion [Ref. 30].

\section{The recently dead}

The Alder Hey Hospital scandal highlighted the removal and retention of children's organs and body parts for scientific study without full parental consent or knowledge [Ref. 31].

confusion and resentment in the research community. They bemoan the rising burden of paperwork, the curtailment of research freedom, expensive delays caused by lengthy application procedures, inconsistent decisions, and in some cases, the halting of entire research programmes by allegedly heavy-handed but misinformed ethics committees. $^{4-7}$ The BMJ recently launched a campaign to revitalize academic medicine which aims to promote better public understanding of research and ensure that high quality studies that will benefit patients are supported rather than suppressed. 
This is the first in a series of three papers that look at research governance from both a theoretical and a practical perspective. We consider definitions of research and governance from different standpoints and attempt to clarify and explain (but not to defend uncritically) the current systems for regulating research. Our main example is the UK National Health Service, but we draw on examples from other countries and sectors. Papers two and three in the series will explore issues of risk, indemnity, and ethics.

\section{WHAT IS RESEARCH?}

Implicit in the human condition is an insatiable curiosity and the desire to acquire and analyse knowledge. For instance:

- A teenager might look for information on the Internet to complete a piece of homework

- A manager might review attendance figures at a sexual health clinic with a view to changing clinic times to increase accessibility

- A public health consultant might study data on the incidence of breast cancer in her locality following the introduction of mammography screening

- An oncology nurse might collect data from patients entered in a trial of a new cancer drug

- A social scientist might analyse the messages from a public access Internet discussion about the safety of vaccines.

All these activities might be perceived as research by the person undertaking them (Box 2). Whether a study is research in the sense that it requires formal regulation and monitoring (e.g. approval from a research ethics committee) depends on: (a) the defined remit of the regulatory body; (b) the specific question being addressed; (c) the method(s) chosen to address the question; (d) the context in which the work takes place; $(e)$ the nature and depth of analysis and interpretation; and $(f)$ the plans for publication and the use to which the findings will be put.

\section{WHAT IS GOVERNANCE?}

Governance is the system of administration and supervision through which research is managed, participants and staff are protected, and accountability is assured. Governance is not the remit of any single institution (indeed, a guiding principle is that it is everyone's business). It is therefore not surprising that tensions exist (and always will exist) between regional, national or international (e.g. European Union) codes of practice; national and European law; and professional standards, norms and values.

In the UK, the main reference point is the Research Governance Framework for Health and Social Care,${ }^{8}$ whose

\section{Box 2 Definitions of research}

The lay person's definition ... .

Research is about asking a question and systematically looking for the answer [Ref. 32].

The medical editor's definition ...

Research is concerned with discovering the right thing to do and audit is about ensuring that it is done right [Ref. 33].

The World Medical Association's definition ...

The primary purpose of medical research involving human subjects is to improve prophylactic, diagnostic and therapeutic procedures and the understanding of the aetiology and pathogenesis of disease [Ref. 17].

The OECD's definition ...

Research is creative work undertaken on a systematic basis in order to increase the stock of knowledge, including knowledge of man, culture and society, and the use of this stock of knowledge to devise new applications [Ref. 34].

\section{The hospital's definition ...}

Research is about creating new knowledge about what works and what doesn't. It provides the foundations for national and/or local agreement about the kind of clinical treatment and care we should be providing, i.e. helps to answer the question 'what is best practice?' [Ref. 35].

The taxman's definition ... .

Research and development for tax purposes takes place when a project seeks to achieve an advance in science or technology [Ref. 36].

The social scientist's definition ...

Research is a codified, scholarly and professional mode of knowledge production that has its prime institutional loci in universities, policy analysis units of government departments or international organizations and private research institutes and produced by academics, think-tank experts and development professionals [Ref. 37].

stated purpose is to enhance ethical and scientific quality, promote good practice, reduce adverse incidents and ensure lessons are learned. The Framework, which reflects EU regulations (see below) sets out the responsibilities of the individuals and organizations involved in research, including funders, researchers, organizations employing researchers, and healthcare organizations ${ }^{8}$ and goes some way to dispelling the persistent view of research management as something separate from the science of research.

\section{GAINING APPROVAL FOR A RESEARCH STUDY}

Different regulatory and approval bodies have different remits and agendas. The question 'does my study need approval by a particular body?' must be answered with reference to what that body considers within its remit, 
Box 3 Overview of processes for governing research in selected countries

\section{Canada and USA}

- Both countries have nationally coordinated and regulated ethics committee structures and procedures and additional provision for review of multi-centre studies. Whereas Canadian Research Ethics Boards are responsible for reviewing and approving clinical trial protocols and informed consent forms for research with human subjects, US Institutional Review Boards formally review all research activities involving human subjects

- Both appear to have other institutional arrangements in place to review, for instance, legal and contract matters, liability or billing issues

- Governmental and regulatory agencies concerned with the conduct of research include the US Office for Human Research Protections and the Canadian Institutes for Health Research. The Canadian national policy statement is notable in acknowledging that studies employing social science methods may require different procedures to those used for clinical or intervention studies.

\section{UK}

- NHS Research Ethics Committees (RECs) review all research involving NHS patients, premises, staff and tissue samples. The same form is used for review of all research projects, with RECs required to provide a decision within 60 working days

- Other committees, such as those in universities, also review healthrelated research

- Research of this kind must also gain formal NHS management approval from the relevant local NHS trust(s) where the study is taking place and all clinical trials of new medicinal products must now gain a European Clinical Trials Database reference before proceeding

\section{China}

- No national ethical review process is in place but individua committees with voluntary processes appear to be developing on an ad hoc and voluntary basis

- No legal or formal system of ethical or research management approval appears to be available through which research involving human subjects can proceed, although international collaborative projects should seek approval from their centre (e.g. in the USA or the UK)

rather than in relation to what the researchers themselves consider to be the key ethical and scientific issues. The different definitions of research used by different bodies reflect their particular agendas and priorities (e.g. pure versus applied, biomedical versus psychosocial, wet versus dry), and are sometimes couched in oppositional terms (that is, describing what research, for their purposes, is not). ${ }^{9}$

In practice, however, projects often prove difficult to classify even with explicit written guidance. ${ }^{10}$ For example, many types of applied research (action research, ${ }^{11}$ evaluation of services, ${ }^{12}$ quality improvement research, ${ }^{13}$ and so on) seek to generate new knowledge as well as providing direct benefits to patients and practitioners locally, so it is meaningless to state which is the 'main' purpose of the project. The inherently fuzzy nature of much contemporary research means that algorithmic tools (in which a flow chart of questions leads to one of two categories: 'research' or 'not research';14 'trial' or 'not trial',15 etc.) may have limited potential for removing ambiguity.

If an official research approval body (such as a local research ethics committee in the UK) deems a particular project outside its remit (e.g. if the study does not involve NHS staff, patients or tissue samples and takes place off NHS premises), this does not mean the project team can pursue their work unrestrained. It would be highly unusual if the study did not fall within the remit of at least one (and possibly several) other regulatory bodies. Clinical audit, for example, will be the remit of the acute or primary care trust under clinical governance arrangements. ${ }^{13,16} \mathrm{~A}$ student PhD study based in a UK university, but with all fieldwork conducted abroad, will be covered by the university under its internal supervision and ethics procedures. A survey of school pupils generally needs approval from the school's board of governors. And so on. In addition, researchers are professionally (though not legally) bound by generic codes of practice (e.g. Declaration of Helsinki ${ }^{17}$ ). And, of course, we all have responsibility to obey the law and behave decently towards our fellow citizens - e.g. following ethical principles of respect for human dignity, beneficence, non-malefience and justice. ${ }^{18}$

There are instances when official regulations appear to have obvious ambiguities. For instance, an investigative journalist employed by a TV company and an academic researcher employed by a university might both collect the narratives of people taking an antidepressant drug. But, whereas the journalist must do no more than stay within the law (e.g., the Data Protection Act), the researcher is bound by an additional set of formal and statutory procedures by virtue of the classification of the study as academic research.

Where there is doubt as to the status of a proposed study, it is quite in order to ask advice from the Central Office for Research Ethics Committees who may also liaise with relevant committee/s (see [www.corec.org.uk] for contact details). Judgement will be applied on a case-bycase basis, drawing on local precedent and the definitions in Box 2.

\section{RESEARCH GOVERNANCE IN AN INTERNATIONAL CONTEXT}

Box 3 gives examples of the broad systems for reviewing and approving research involving human participants outside the UK. They are the product of the prevailing social, healthcare and research environments in different countries and will inevitably vary in focus and aims. ${ }^{19}$ Some carry legal weight or are formalized in some other way, others have looser terms of reference or are entirely voluntary. Similarly, professional codes and guidance vary widely within and across countries. ${ }^{19}$ 


\begin{tabular}{|c|c|c|}
\hline & What they did in $1951 \ldots$ & What they need to do now .... \\
\hline Ethical review & $\begin{array}{l}\text { Ethical issues were considered broadly via the clinical } \\
\text { academic research culture and the Hippocratic Oath. } \\
\text { Ethical approval was not sought as no relevant ethics } \\
\text { committee existed at the time }\end{array}$ & $\begin{array}{l}\text { An NHS Multi-centre Research Ethics Committee } \\
\text { would now need to review the research proposal. } \\
\text { Relevant Local Research Ethics Committees may then } \\
\text { need to be informed of the study }\end{array}$ \\
\hline Contacting respondents & $\begin{array}{l}\text { Doctors within the study were contacted through the } \\
\text { British Medical Association that dispatched the } \\
\text { questionnaire and letters on behalf of the study team }\end{array}$ & $\begin{array}{l}\text { There is little difference in the process today. The BMA } \\
\text { holds this list of doctors and, as recent data protection } \\
\text { legislation means the study team would be unable to } \\
\text { have direct access to doctors' contact details, they } \\
\text { would be reliant on the cooperation of the BMA to } \\
\text { undertake this work }\end{array}$ \\
\hline Consent & $\begin{array}{l}\text { Consent to participate in the study was gained by } \\
\text { respondents returning the completed questionnaire to } \\
\text { the study team in } 1951 \text {. Subsequent questionnaires } \\
\text { were then returned on the same basis. Individuals } \\
\text { could withdraw from the study at any time by simply } \\
\text { expressing the wish to do so }\end{array}$ & $\begin{array}{l}\text { Consent for follow-up may now be required when } \\
\text { respondents are first contacted, allowing them to opt } \\
\text { in or out of subsequent questionnaires. Given the } \\
\text { longitudinal nature of the study, the extent of the study } \\
\text { and future contact may not be known at the outset } \\
\text { and, if this is the case, ethics committees may require } \\
\text { consent to be gained at various stages of the study }\end{array}$ \\
\hline Access to data & $\begin{array}{l}\text { Cause specific mortality was monitored prospectively } \\
\text { from 1951-2001 with information originally available } \\
\text { from death certificates provided by the UK Registrar- } \\
\text { General }\end{array}$ & $\begin{array}{l}\text { Death certificates now need to be formally flagged in } \\
\text { order to gain this information. To ensure this process is } \\
\text { in place, the study team sought clearance from the } \\
\text { appropriate approvals body, the Patient Information } \\
\text { Advisory Group (see paper } 2 \text { ) }\end{array}$ \\
\hline Data protection & $\begin{array}{l}\text { Throughout the study, the team have followed-up non- } \\
\text { respondents who are not known to have died. This was } \\
\text { originally an informal process of contacting the } \\
\text { respondents' GP }\end{array}$ & $\begin{array}{l}\text { Recent data protection legislation means that } \\
\text { approvals must be sought to ensure that the study } \\
\text { team can follow-up non-responders in this way }\end{array}$ \\
\hline Reporting & $\begin{array}{l}\text { Dissemination and reporting of findings was via peer } \\
\text { reviewed journals to a wide audience }\end{array}$ & $\begin{array}{l}\text { Little has changed, although editorial guidance now } \\
\text { requires more information regarding contributors, } \\
\text { guarantors and competing interest statements for all } \\
\text { papers, as evidenced in the most recent report of } \\
\text { findings up to } 2001 \text { [Ref. 24] }\end{array}$ \\
\hline
\end{tabular}

This international variation is more than a curiosity. Although international standards for research have been encouraged since Nuremberg, for studies that span several countries, governance requirements in the partner centres may still differ to such an extent that it is impossible to achieve a single common protocol for recruiting participants, gaining informed consent, managing the project, and storing data. ${ }^{6}$ As with all complex research studies, time must be built into the planning and preparation stage for multiple applications to be processed.

Where systems are not in place or appear inadequate for the task at hand, researchers may find it useful to refer to generic guidance (e.g. Declaration of Helsinki, ${ }^{17}$ International Conference on Harmonisation of Good Clinical Practice, ${ }^{20}$ MRC Guidelines on Research in Developing Countries $^{21}$ _ see Box 4 for further examples). However, these recommendations are not always legally binding and may be differently interpreted (or prove impossible to implement) in different countries. For example, all the international guidelines relating to health research recom- mend local ethical review, but ethics committees have yet to become a worldwide phenomenon.

Member countries of the European Union are increasingly encouraged to work together to achieve convergence of policies in a number of fields including research and development. An EU Directive on 1 May 2004 introduced new legal restrictions on the testing of medical products, including an onus on the lead researcher to register all pharmaceutical trials at inception and ensure that appropriate insurance arrangements are in place. ${ }^{22}$ The implementation process has been a cause for concern, not least in questioning whether important publicly funded research may falter due to the rising complexity and costs associated with increased bureaucracy.

\section{IMPLICATIONS FOR SERVICE ORGANIZATIONS}

In the UK, a healthcare organization that hosts research (that is, allows research to be undertaken on its premises) has a number of statutory responsibilities including duty of 
International / EU codes and regulations relating to health research

- The first major international code of ethical principles in medical research was the Declaration of Helsinki, produced by the World Medical Association in 1964. The Declaration was last up-dated in 2000 [www.wma.net/e/policy/b3.htm] with related documents [www.wma.net/e/ethicsunit/helsinki.htm]

- Council for International Organizations of Medical Sciences (CIOMS) established by WHO and UNESCO has provided international guidelines for biomedical research involving human subjects [www.cioms.ch/frame_guidelines_nov_2002.htm]

- The Council of Europe produced the Convention on Human Rights Protection and Biomedical Science and more recently a protocol on Biomedical research [www.coe.int/T/E/Com/Files/Themes/Bioethics/default.asp]

- The International Conference on Harmonisation of Technical Requirements for Registration of Pharmaceuticals for Human Use (ICH) promotes the harmonization of the regulation of pharmaceutical drugs. 1996 Good Clinical Practice guidelines [www.ich.org] under guidelines and efficacy topics

- The World Health Organization has an ethics programme and associated publications [www.who.int/ethics/en]

- European Union Clinical Trials Directive 2001/20/EC relates to the conduct of clinical trials on medicinal products for human use and new legislation implemented in Member States in May 2004 [http://europa.eu.int/eur-lex/pri/en/oj/dat/2001/__121/__12120010501en00340044.pdf].

\section{Guidance on conducting research in developing countries}

- The Medical Research Council has published an ethics guide on research involving human participants in developing societies [http://www.mrc.ac.uk/ pdf-devsoc.pdf]

- The European Group on Ethics in Science and New Technologies published their discussions of the ethical aspects of clinical research in developing countries [http://europa.eu.int/comm/european_group_ethics/docs/tb1oc_en.pdf]

- The Nuffield Council on Bioethics has produced a report on The Ethics of Research Related to Healthcare in Developing Countries [http:// www.nuffieldbioethics.org/go/ourwork/developingcountries/introduction].

\section{UK Research Governance and Ethics}

- The Medical Research Council Ethics and Best Practice pages include guidelines on clinical trials, ethics and peer review [http://www.mrc.ac.uk/index/ publications/publications-ethics_and_best_practice.htm]

- The Department of Health Research Governance pages include information on the development of policy, guidance on specific issues and implementation plans [http://www.dh.gov.uk/PolicyAndGuidance/ResearchAndDevelopment/ResearchAndDevelopmentAZ/ResearchGovernance/fs/ en\#4840302]

- The NHS R\&D Forum have produced a documentation guide for research governance which provides links to all relevant sites [http:// www.rdforum.nhs.uk/workgroups/primary/pcinfoguide/introduction.htm] and provides a list of contact details in order to obtain local NHS R\&D approval for research [http://www.rdforum.nhs.uk/links/locallinks.htm]

- The Central Office for Research Ethics Committees (COREC) provides the most up-to-date information and forms relating to NHS ethical review, including New Operational Procedures [http://www.corec.org.uk/ ]

- Ethics Research Information Catalogue (ERIC) holds a collection of articles related to the ethics of medical research on humans at [http://www.eric-online.co.uk/index.php]

- The Medicines and Healthcare products Regulatory Agency (MHRA) provides information on the Clinical Trials Directive [http://www.mhra.gov.uk/ ] and a joint site between the DH and MHRA has a Clinical Trials Toolkit [http://www.ct-toolkit.ac.uk]

- Each university in the UK has its own rules, regulations and processes [http://www.scit.wlv.ac.uk/ukinfo/].

care to all patients, ensuring scientific review of proposals and monitoring research. ${ }^{8}$ It incurs additional responsibilities for the initiation, management and conduct of a research project if it decides to act as a research sponsor. ${ }^{8}$ The NHS R\&D Forum (see Box 4) provides a list of NHS institutions who act as research hosts and/or sponsors.

These new infrastructure requirements place a high burden on NHS organizations. Historically, little emphasis was placed on the management and administration of research studies, which tended to be seen as the creative pursuits of individual clinicians. To some extent, then, service organizations must undergo a cultural change as well as invest in the necessary infrastructure to support research. Recent surveys have shown that most health service staff feel positive about the principles and aspirations of the Research Governance Framework but find them confusing and difficult to implement in practice. ${ }^{1,5,8}$

There is also the issue of proportionality-i.e. the punishment should fit the crime. The principles, structures and systems associated with research governance apply whether undertaking a large multi-centre clinical trial or a small local project. In secondary care (e.g. acute hospital trusts), considerable research infrastructure already exists, and the implementation of research governance has been fairly non-contentious. This has not been the case in primary care, where research has not historically been part of core business and $\mathrm{R} \& \mathrm{D}$ infrastructure is underdeveloped. ${ }^{23}$ PCTs who are just beginning to develop a research culture and build research capacity must make considerable short-term investment in the initial setting-up of systems - a step that many will find prohibitive.

\section{IMPLICATIONS FOR INDIVIDUAL RESEARCHERS}

Table 1 draws on Richard Doll's 50-year longitudinal study of the outcome of smoking in British doctors to explore how the research process and governance procedures have changed over time. ${ }^{24}$ It points to several areas relating to 
research governance and ethics that researchers must consider before commencing a study, many of which are established features of good research practice, but until recently only the individual researcher was officially accountable for them.

Some of the changes highlighted in Table 1 have raised concerns about over-regulation, 4,6 and the creation of additional and unwelcome layers of bureaucracy across the research environment. Doll himself was willing to go to prison in defiance of new regulations, believing they are suffocating clinical medical research. Many of these areas will be discussed in more detail in papers two and three of this series.

\section{CONCLUSION}

Only time will tell if research governance procedures will achieve the goal of raising standards, protecting participants and assuring quality - and whether the inevitable constraints on research freedom will be worth the candle. Nevertheless, the procedures are now official, and cutting corners constitutes fraud and/or professional misconduct. Depending on the particular regulations breached, the researcher may face criminal charges, removal or restriction of professional privileges, loss of institutional indemnity, or dismissal from employment. Where genuine ambiguity exists about the status of a proposed study, it may be a false economy to try to sell it as non-research in order to avoid having to complete the paperwork, since if the work is subsequently submitted to an academic journal, confirmation of research ethics approval may be a condition for publication.

On a positive note, NHS research ethics committees are now required to deliver decisions on valid applications within 60 working days, with similar arrangements throughout the $\mathrm{EU}^{6}$. They are also being encouraged to move from an ethos of policing research to one of quality assurance and facilitation. The UK Department of Health is reviewing the barriers to research caused by new governance systems. ${ }^{25}$ Hopefully, this will lead to a slackening of red tape, streamlining of procedures, and specific measures in research fields for which current regulations have proved unworkable.

Acknowledgment Our thanks go to the late Sir Richard Doll for his comments on this paper.

\section{REFERENCES}

1 Shaw S, Macfarlane F, Carter YH, Letley L. Developing primary care research teams: a qualitative interview study in UK general practice. Aust J Primary Health 2005;11:24-31

2 Oliver S, Clarke-Jones L, Rees R, et al. Involving consumers in research and development agenda setting for the NHS: developing an evidencebased approach. Health Technol Assess 2004;8:1-148
3 McNeill PM. The Ethics and Politics of Human Experimentation. Cambridge: Cambridge University Press, 1993

4 Warlow C. Over-regulation of clinical research: a threat to public health. Clin Med 2005;5:33-8

5 Royal College of General Practitioners. Informal Consultation On Barriers To Research Created By Over-Regulation, Ethics Committees. etc. London: Royal College of General Practitioners Research Group, 2004

6 Gennery B. Academic clinical research in the new regulatory environment. Clin Med 2005;5:39-41

7 Wald DS. Bureaucracy of ethics applications. BMJ 2004;329:282-4

8 Department of Health. Research Governance Framework for Health and Social Care, 2nd edn. London: Department of Health, 2005

9 Lynn J. When does quality improvement count as research? Human subject protection and theories of knowledge. Qual Safety Health Care 2004;13:67-70

10 Wade DT. Ethics, audit and research: all shades of grey. BMJ 2005;330:468-71

11 Greenhalgh T, Collard A, Begun N. Sharing stories: complex interventions for diabetes education in minority ethnic groups who do not speak English. BMJ 2005:330:632

12 Bradley F, Wiles R, Kinmonth A, Mant D, Gantley M. Development and evaluation of complex interventions in health services research: case study of the Southampton heart integrated care project. BMJ 1999;318:711-15

13 Lo B, Groman M. Oversight of quality improvement: focusing on benefits and risks. Arch Intern Med 2003;163:1481-6

14 NHS Research and Development Forum. Guidance On Developing Procedures Within NHS Organisations For Appropriate Authorisation And Management of Research And Related Projects. London: NHS R\&D Forum, 2005 [www.rdforum.nhs.uk/docs/ categorising_projects_guidance.doc]

15 Medicine and Healthcare Products Regulation Agency. Clinical Trials Algorithm. London: MHRA, 2005 [http://medicines.mhra.gov.uk/ ourwork/licensingmeds/types/clintrialalgorithm.pdf]

16 Casarett D, Karlawish JHT, Sugarman J. Determining when quality improvement initiatives should be considered research: proposed criteria and potential implications. JAMA 2000;283:2275-80

17 World Medical Association. Declaration of Helsinki. Helsinki: WMA General Assembly, 1964

18 The National Commission for the Protection of Human Subjects of Biomedical and Behavioural Research. The Belmont Report: Ethical Principles and Guidelines for the Protection of Human Subjects of Biomedical and Behavioural Research. Washington, DC: US Government Printing Office, 1979

19 Barrett G, Coleman MP. Ethical and political issues in the conduct of research. In Bowling A, Ebrahim S, eds. Handbook Of Health Research Methods: Investigation, Measurement And Analysis. Buckingham: Open University Press, 2005

20 Guideline for good clinical practice guide. In International Conference on Harmonisation of Technical Requirements for Registration of Pharmaceuticals for Human Practice. Geneva: ICH, 1996

21 Medical Research Council. Research Involving Human Participants In Developing Societies: Ethical Guidelines For MRC-Sponsored Studies. London: MRC, 2004

22 European Parliament and the Council of the European Union. Directive 2001/20/EC. Luxembourg: European Parliament, 2001

23 Chen F, Majeed A. Primary care trusts and primary care research. BMJ 2005;330:56-7

24 Doll R, Peto R, Boreham J, Sutherland I. Mortality in relation to smoking: 50 years' observations on male British doctors. BMJ 2004;328:1519-28

25 Department of Health. Research for Patient Benefit Working Party: Final Report. London: Department of Health, 2004 
26 Fairchild AL, Bayer R. Uses and abuses of Tuskegee. Science 1999;284:919

27 Gray BH. Human Subjects In Medical Experimentation: A Sociological Study Of The Conduct And Regulation Of Clinical Research. New York: Wiley, 1975

28 Lackey DP. Clinical trials in developing countries: a review of the moral issues. Mount Sinai J Med 2001;68:4-12

29 Hyder AA, Wali SA, Khan AN, Teoh NB, Kass NE, Dawson L. Ethical review of health research: a perspective from developing country researchers. J Med Ethics 2004;30:68-72

30 Smith G, Bartlett A, King M. Treatments of homosexuality in Britain since the $1950 \mathrm{~s}$ - an oral history: the experience of patients. BMJ 2004;328:427-9

31 Dewar S, Boddington P. Returning to the Alder Hey report and its reporting: addressing confusions and improving inquiries. $J$ Med Ethics 2004;30:463-9
32 INVOLVE. Getting Involved In Research: A Guide For Consumers. London: INVOLVE, 2001 [www.invo.org.uk/pdfs/guide_for_consumers.pdf]

33 Smith R. Audit \& Research. BMJ 1992;305:905-6

34 OECD. The Measurement of Scientific and Technical Activities. Standard Practice for Surveys of Research and Experimental Development-Frascati Manual, 1994 [www1.oecd.org/dsti/stat-ana/prod/eas_fras.htm]

35 United Bristol Healthcare NHS Trust. What is Clinical Audit?, Vol. 2.2. Bristol: UBH NHS Trust, 2005 [www.ubht.nhs.uk/clinicalaudit/ docs/HowTo/WhatisCA.pdf]

36 Department of Trade and Industry. Guidelines On The Meaning Of R\&D For Tax Purposes. London: DTI, 2004 [www.innovation.gov.uk/randd/ index.asp?lvl $1=2 \& \operatorname{lvl} 2=1 \& \operatorname{lvl} 3=0 \& \operatorname{lvl} 4=0]$

37 Stone D. Getting research into policy. In Global Development Network 2002 [www.gdnet.org/rapnet/pdf/Beyond\%20Economics\%20Stone.pdf] 